\title{
Aneurisma micótico de la arteria glútea superior, complicación de una endocarditis bacteriana
}

\author{
Mycotic aneurism of the superior gluteal artery, \\ complication of an endocarditis
}

Raquel Fernández-González'1, María Bustillo-Casado², Alfonso Varela-Fariña' ${ }^{1}$ Ines Fernández-Regal'
${ }^{1}$ Servicio de Medicina Interna. ${ }^{2}$ Servicio de Medicina Interna. Unidad de Infecciosas. Complejo Universitario Hospitalario de Ourense, España

\section{Resumen}

El aneurisma micótico de la arteria glútea superior es excepcional. Tras una revisión de las publicaciones de aneurismas de esta arteria tan solo se han encontrado documentados seis casos. Presentamos el caso de un varón de 65 años con un aneurisma micótico en la arteria glútea superior presentada en el seno de una endocarditis bacteriana.

Palabras clave: Aneurisma. Micótico. Endocarditis.

\section{Caso clínico}

Varón de 65 años con deterioro cognitivo leve de origen etílico e institucionalizado recientemente, sin otros antecedentes de interés. Cuatro días antes del ingreso presenta inflamación en el glúteo izquierdo. Se realiza una analítica donde destaca una hemoglobina $4,5 \mathrm{mg} / \mathrm{dl}$ normocítica-normocrómica, ingresando para estudio. Tras 24 horas de hospitalización presenta fiebre, hemiparesia derecha y dolor abdominal. Se extraen hemocultivos, se inicia antibioterapia empírica con amoxicilina-clavulánico y se solicita prueba de imagen donde muestra ACVA isquémico occipital izquierdo y un gran hematoma glúteo izquierdo de 20×3×6 cm con sangrado activo a expensas de la arteria

\begin{abstract}
Mycotic aneurysm of the superior gluteal artery is exceptional, there are only six cases reported. This is the case of a 65-year-old man with a mycotic aneurysm, the first symtom of a bacterial endocarditis.
\end{abstract}

Keywords: Aneurysm. Mycotic. Endocarditis. glútea superior izquierda. Se realiza de forma urgente cateterización supraselectiva y embolización de la rama, lográndose el cese del sangrado (imagen 1). En los hemocultivos crece Streptococcus gallolyticus spp. gallolyticus .Por el cuadro clínico, los hallazgos radiológicos y el resultado microbiológico se plantea el diagnóstico de endocarditis, que se confirma mediante ecocardiograma. La evolución posterior del paciente fue favorable, no presentando nuevos eventos embólicos 0 resangrado del aneurisma. Se desestimó la intervención quirúrgica de la válvula por la situación sociofamiliar y el deterioro cognitivo basal.

Imagen 1. La arteriografía selectiva muestra el aneurisma de la arteria glútea superior (flecha)

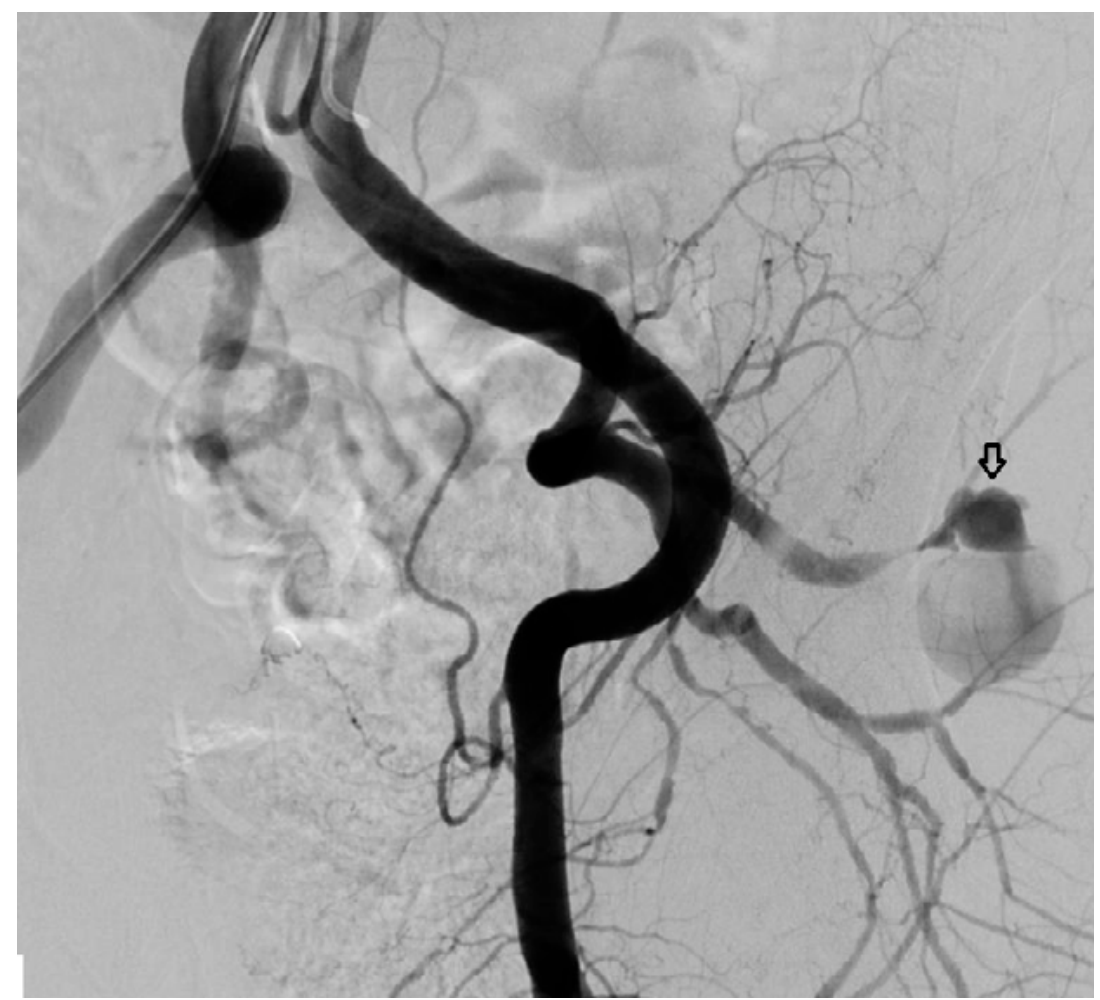




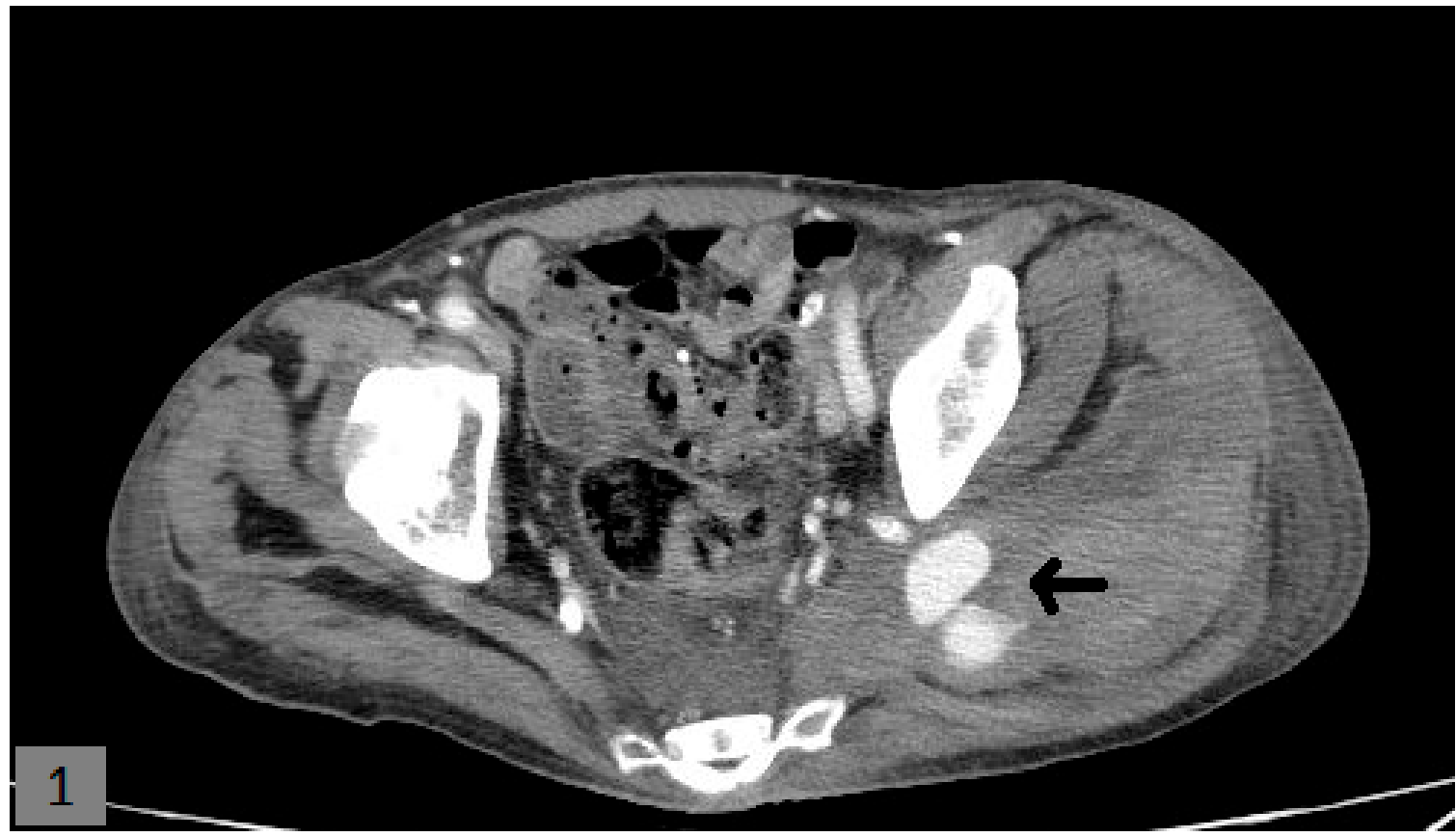

\section{Discusión}

El aneurisma micótico como complicación de una endocarditis ocurre en un $2-4 \%$ de las endocarditis, aunque es probable que esta cifra este infraestimada' ${ }^{1}$. La mayoría son a nivel intracraneal, y en localizaciones extracraneales las más frecuentes son las arterias viscerales o de la región proximal de miembros inferiores. La localización más frecuente es en bifurcaciones, y por su origen embolígeno suelen ser múltiples². Los pseudoaneurismas de cualquier origen de la arteria glútea superior suponen menos del $1 \%$ y la mayoría son resultado de un traumatismo pélvico o heridas inciso-contusas. Causas menos frecuentes son la infección, poliarteritis nodosa, arterioesclerosis y degeneración mucoide intimomedial ${ }^{3}$. El primer caso de aneurisma micótico de la arteria glútea superior se describió en $1992^{4}$. Desde entonces sólo se han documentado 6 casos. Tienen una alta tasa de mortalidad debido a la tendencia a la rotura por presentar paredes delgadas y friables. No se ha identificado un predictor de ruptura, aunque parece no guardar relación con el tamaño; a diferencia de los aneurismas no infecciosos ${ }^{1}$. La prueba definitiva para su diagnóstico es la angiografía, si bien otras pruebas de imagen como TC o RMN han mostrado buena sensibilidad y especificidad ${ }^{1}$ (imagen 2). Su manejo depende de su tamaño y localización. Los de localización intracraneal se tratan de forma conservadora mediante antibióticos y controles, salvo complicaciones que requieran tratamiento endovascular1-2. En los de localización extracraneal, clásicamente manejados mediante cirugía abierta, en los últimos años aumenta la evidencia de que un abordaje endovascular puede ser la primera línea en el tratamiento ${ }^{5}$.

\section{Bibliografía}

1. European Association for Cardio-Thoracic Surgery (EACTS), the European Association of Nuclear Medicine (EANM). 2015 ESC Guidelines for the management of infective endocarditis. Eur Heart J. 2015; 29: 29.

2. Baddour LM, Wilson WR, Bayer AS, et al. Infective Endocarditis in Adults: Diagnosis, Antimicrobial Therapy, and Management of Complications: A Scientific Statement for Healthcare Professionals From the American Heart Association. Circulation. 2015; 132:1435.

3. Schorn B, Reitmeier F, FalkV, et al. True aneurysm of the superior gluteal artery: case report and review of the literatura. J Vasc Surg. 1995; 21: 851-2.

4. Grand C, Delcour C, Bank WO, et al. Emergency embolization of a mycotic aneurysm of the superior gluteal artery: case report. Cardiovasc Intervent Radiol. 1992; 15:117-9.

5. Schindera ST, Anderson SE, Triller J. Coil embolization of an infected superior gluteal artery pseudoaneurysm caused by methicillin-resistant staphylococcus aureus. Vasa. 2005; 34:62-5 